\title{
THE ONGOING CANON DEBATE
}

(Perdebatan Kanon yang Sedang Berlangsung)

Diterjemahkan Oleh:

Yowenus Wenda, M.Pd

2015070011

PROGRAM DOCTORAL (S3)

PROGRAM STUDI PENDIDIKAN AGAMA KRISTEN

SEKOLAH TINGGI AGAMA KRISTEN PROTESTAN NEGERI (STAKPN) BURERE SENTANI-PAPUA

TAHUN 2015 


\title{
PERDEBATAN KANON YANG SEDANG BERLANGSUNG ${ }^{1}$
}

Flip Schutte (Witbank) Departemen Studi Perjanjian Baru

University of Pretoria

\begin{abstract}
Abstrak
Tujuan dari tinjauan artikel ini adalah untuk berpartisipasi di dalam " debat kanon "di kalangan sarjana Alkitab. Koleksi esai, perdebatan tentang kanon diedit oleh Lee Martin McDonald dan James A Sanders dan diterbitkan pada November 2002 berfungsi sebagai titik keberangkatan. Tiga puluh dua esai dalam buku ini memberikan ringkasan penelitian terbaru dan karena itu perlu menyediakan latar belakang untuk partisipasi yang berarti dalam perdebatan saat ini. " debat kanon" oleh McDonald \& Sanders mungkin adalah koleksi yang paling komprehensif dari esai yang pernah diterbitkan pada kanon formasi dalam Yudaisme dan Kristen. Volume 662 halaman ini termasuk esai pada kedua Perjanjian Lama dan Perjanjian Baru serta apokripa dan pseudepigrapha. Esai menyediakan terjemahan dari sebagian besar sumber-sumber primer kuno serta ringkasan bermakna tentang debat ilmiah, selain menyediakan panduan yang berguna untuk literatur ilmiah yang luas pada subjek. Artikel ini berpendapat bahwa Anda sekalian telah menemukan kanon, Anda dapat mengalaminya di manapun, tidak hanya di dalam teksteks kanonik.
\end{abstract}

\section{PENGANTAR}

Selama beberapa tahun terakhir, sejumlah buku dan artikel dengan kanon dan kanonisitas sebagai topik telah melihat cahaya (misalnya, Metzger 1987; Mack 1995; McDonald 1995; Funk 1996; Jenner \& Wiegers 1998; Saebo 1998; Van Aarde 2001, 2004). Universitas The Leiden untuk studi agama-agama (LISOR) mengadakan konferensi Internasional di Leiden (Belanda) 9-10 Januari 1997. Makalah-makalah yang disajikan diterbitkan oleh E J Brill Publishing House sebagai bagian dari seri-seri "Studi dalam sejarah

\footnotetext{
${ }^{1}$ Review Article:. McDonald, L M \& Sanders, J M 2002. The Canon debate. Peabody, MA: Hendrickson Publishers. P J W (Flip) Schutte is a PhD student in the Departement of New Testament Studies at the Faculty of Theology, University of Pretoria, under the supervision of Prof Dr Andries G van Aarde.
} 
agama" pada tahun 1998 (lihat Van der Kooij \& Van der Toorn 1998). Untuk alasan yang menarik ini baru dalam kanon dan otoritas dan validitasnya, editor meminta meninjau artikel dari buku ini. Memang, publikasi koleksi tiga puluh dua esai,

berjudul debat kanon, oleh sarjana Perjanjian Baru Lee Martin McDonald dan sarjana Perjanjian Lama James A Sanders pada tahun 2002 (Hendrickson Publishers) manfaat sebuah artikel lebih dari sekedar meninjau. Tujuan dari artikel ini karena untuk membuka isi buku kepada para pembaca. Artikel meluas suatu undangan ke pembaca untuk membentuk pendapat mereka sendiri atas isu yang sangat diperdebatkan dan penting ini.

Apa yang membuat debat kanon oleh editor Lee Martin McDonald dan James A Sanders selalu direkomendasikan ini merupakan fakta bahwa hal itu mungkin merupakan koleksi esai dari yang paling komprehensif yang pernah diterbitkan pada pembentukan kanon di Yahudi dan Kekristenan. Volume 662 halaman ini termasuk esai pada kedua Perjanjian Lama dan Perjanjian Baru. "debat kanon" yang sangat berhubungan dengan masing-masing Perjanjian dibahas secara menyeluruh. Publikasi tidak hanya berurusan dengan buku-buku yang merupakan bagian dari kanon, tetapi juga mengeluarkan dari kanon, Yahudi dan Kristen apokrif dan pseudepigrapha.

Lebih dari tiga puluh sarjana mengambil bagian di perusahaan ini, dipimpin oleh Lee Martin McDonald dan James A Sanders. Yang pertama adalah utama dan profesor Studi Alkitab di Perguruan Tinggi Arcadia Wolfville, Nova Scotia, dan Sanders adalah pendiri dan presiden Naskah Alkitab Kuno untuk Pusat Pelestarian dan penelitian di Claremont, California.

\section{PENGANTAR KEPADA PERDEBATAN}

Pendapat saya adalah bahwa keberadaan "kanon" seperti halnya kehidupan Masyarakat Kristen, bukanlah merupakan suatu peristiwa yang kekal seperti kebanyakan orang berpikir tetapi hal ini merupakan suatu peristiwa yang menjadi ada oleh karena situasi historis tertentu. Kemudian memenuhi fungsi tertentu di dalam suatu masyarakat dan kemudian dengan berlalunya waktu dan situasi baru tiba pada peristiwa, hal itu bisa menghilang lagi.

Ketika Adriaanse (1998: 315) menaruh itu: "Kanon menurut sejarah dikondisikan berbagai hal; sebetulnya, mereka mempunyai jangka waktu/zaman untuk persiapan, jangka waktu/zaman mereka dibentuk - kanonisasi dalam arti yang tepat - jangka waktu/zaman mereka menjadi operatif, jangka waktu/zaman menjadikan mereka disintegrasi dan tidak 
berguna dan akhirnya, waktu lampau mereka sempurna, jangka waktu/zaman dari mereka hilang lengkap." Oleh karena itu salah satu kebutuhan untuk mendekati "debat kanon" dari sudut pandang bahwa keberadaan kanon merupakan suatu proses dari "kanonisasi" dan "decanonisasi".

Decanonisasi dapat terjadi dalam berbagai bentuk. Hal ini dapat terjadi sebagai akibat dari pembongkaran kanon. Vos (1998: 363) dikatakan sebagai berikut:

Analisis historis-kritis Alkitab telah menyebabkan dekomposisi dan kehancuran (viz. 'de-konstruksi') hal itu yang dulu dianggap membentuk satu kesatuan. Proses seperti decanonisasi bisa berkembang di bawah permukaan, hampir sengaja, sebagai akibat dari karya percaya Kristen. Pada kenyataannya, seluruh penyelidikan atas inti dari kanon sebenarnya dapat beroperasi untuk menghancurkan kanon. Dengan cara ini kanon menjadi korban keinginan sendiri.

Di tempat kedua, proses decanonisasi terjadi ketika situasi timbul di mana Alkitab hampir tidak pernah dibaca. Kemudian kanon berhenti menjadi kanon karena tidak lagi memenuhi fungsi direktif dan standar untuk kehidupan orang-orang yang mematuhi kanon sebagai kanon mereka. Vos (1998: 363) merumuskan konsekuensi dari "kebebasan" seperti berikut.

Kebebasan pikiran dan decanonisasi berjalan beriringan karena kebebasan ini yang berdiri bertentangan dengan permintaan bahwa Alkitab, oleh hak prerogatif, harus direktif dan standar untuk kehidupan spiritual. Di bawah naungan kebebasan ini, banyak "tercerahkan" Kristen menerima agama-agama lain dan beberapa ateis menolak setiap bentuk wahyu.

(Vos 1998: 367)

Satu dapat menyatakan bahwa kanon Kristen telah dibawa ke dalam mendiskreditkan di abad terakhir karena bentrok dengan ide-ide modern tentang pluralisme dan kebebasan pikiran. Vos (1998: 368) menyatakan bahwa kritik kanon dan decanonisasi bisa ditafsirkan sebagai bukti keuntungan suatu filosofi hidup yang tidak kanonik seperti perikemanusiaan.

Saya yakin bahwa kanon orang Kristen saat ini sedang dalam zamannya dari disintegrasi, menggunakan kata-kata Adriaanse, karena alasan Vos dinyatakan di atas. Paradigma bahwa kita berpikir dan hidup ini telah berubah secara radikal, dan kita tidak membaca Alkitab lagi seolah-olah itu merupakan suatu ramalan ilahi yang berbicara langsung tangan Tuhan. Ia telah kehilangan statusnya berkondisi sebagai "Firman Allah".

Dengan latar belakang ini, dan sudut pandang saya membaca The Canon Debate (Debat Kanon) oleh McDonald dan Sanders (2002). 


\section{SUDEPRESENTAS PRESENTAS}

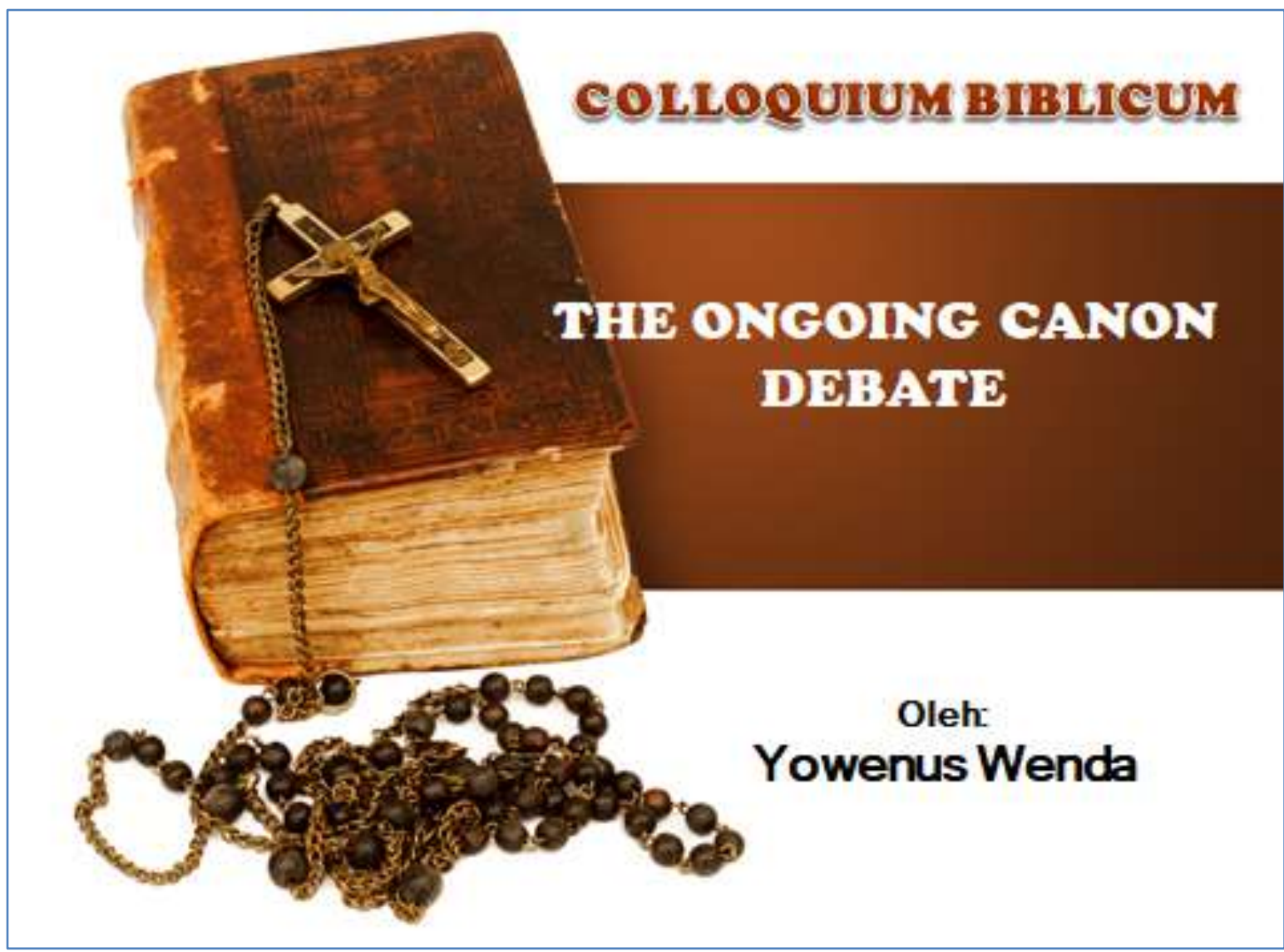

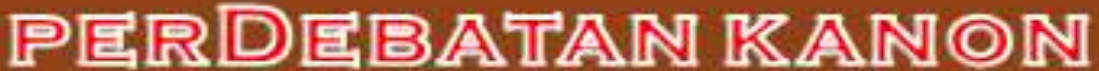

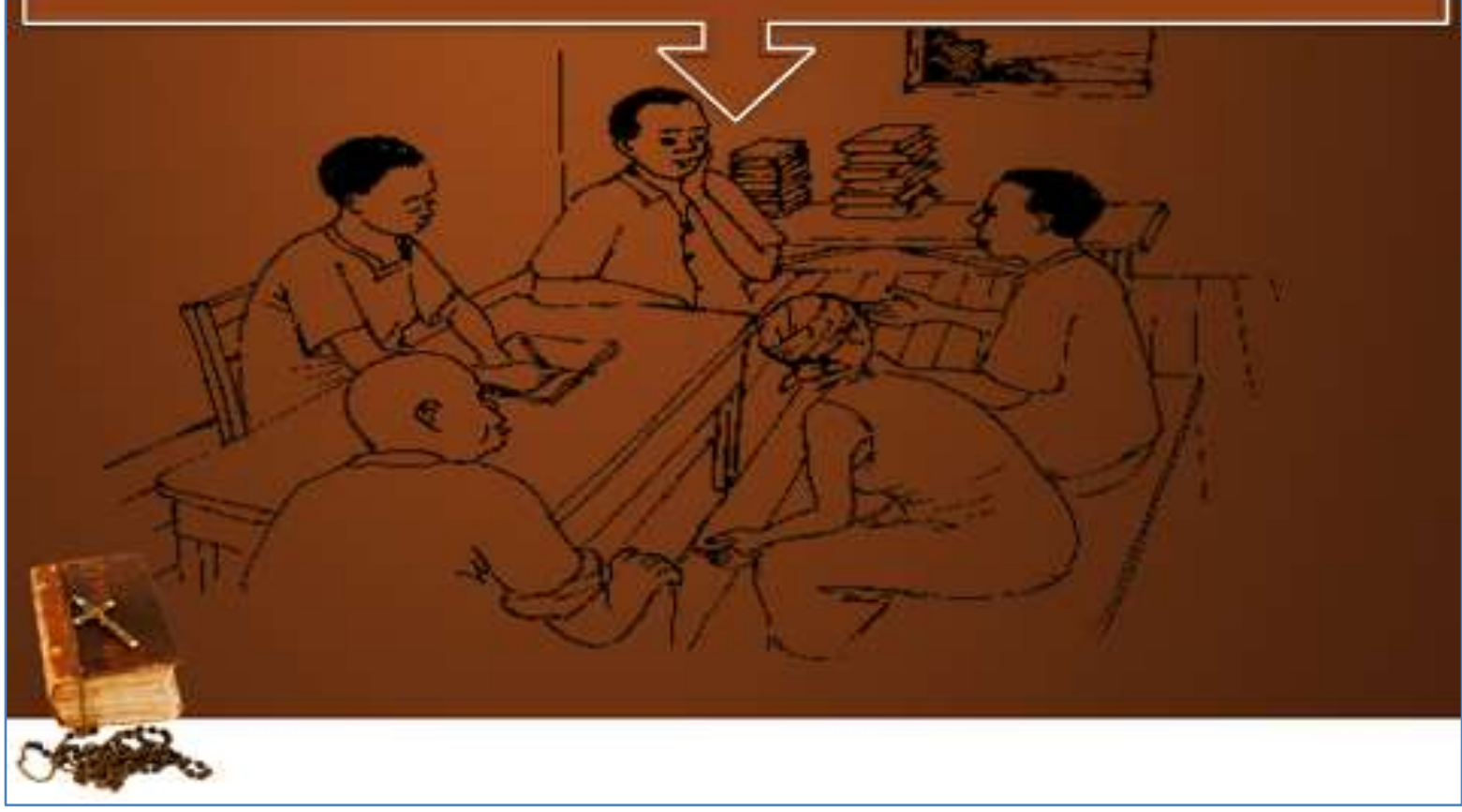


Kanon = Yurari yang berarti tongkat pengukur, standart

Debat kanon sangat berhuburgan dengan masing2 perjanjian secara menyeluruh.

James A Sanders = pendiri dan presiden Naskah Alkitab Kuno

Lee Martin LcDonald = profesor Shod

PB

\section{DEBAT KANON}

\section{"DebatKanon"oleh McDonald \&}

Sanders mungkin adalah koleksi yang paling komprehensif dari esai yang pernah diterbitkan pada kanon formasi dalam Yudaisme dan Kristen.

Volume 662 halaman ini termasuk esai padakeduaPL\& PB serta apokripadan pseudepigapha
Tujuan = berpartisipasi di dalam " debatkanon"di kalangan sarjana Alkitab.

Tiga puluh dua esai dalam bukuinimemberikan ringkasan penelitian terbaru.

Esaimanyediakan terjemahan dari sebagian besar sumber-sumber primer Kunoserta ringkasan bermaknatenteng debat illiah.

“Anda sekalian telah manemikan kanon, Anda dapat mengalaminga di manapun, tidak hanya di dalam teks teks kanorik."

"Kanon" seperti halnya kehidupan

Masyarakat Kristen, bukanlah merupakan suatu peristiwa yang kekal seperti kebanyakan orang berpikir tetapi hal ini merupakan suatu peristiwa yang menjadi ada

oleh karena situasi historis tertentu.

Adriaanse (1998: 315) : "Kanon menurut sejarah dikondisikan berbagai hal. (Mempunyai jangkawaktuzaman untuk persiapan, dibentuk kanonisasi dalam arti yang tepat-dsb.

\section{PENGANTAR KEPADA}

\section{PERDEBATAN}

"Debat Kanon" dari sudut pandang bahwa keberadaan kanon merupakan suatu proses dari Tkanonisasi" dan -decanonisasi.

Decanonisasi dapat terjadi dalam berbagai bentuk. Hal ini dapat terjadi sebagai akibat dari pembongkaran kanon.
Proses decanonisasi terjadi ketika sithasi timbul di mana Alkitab hampir tidak permah dibaca. 


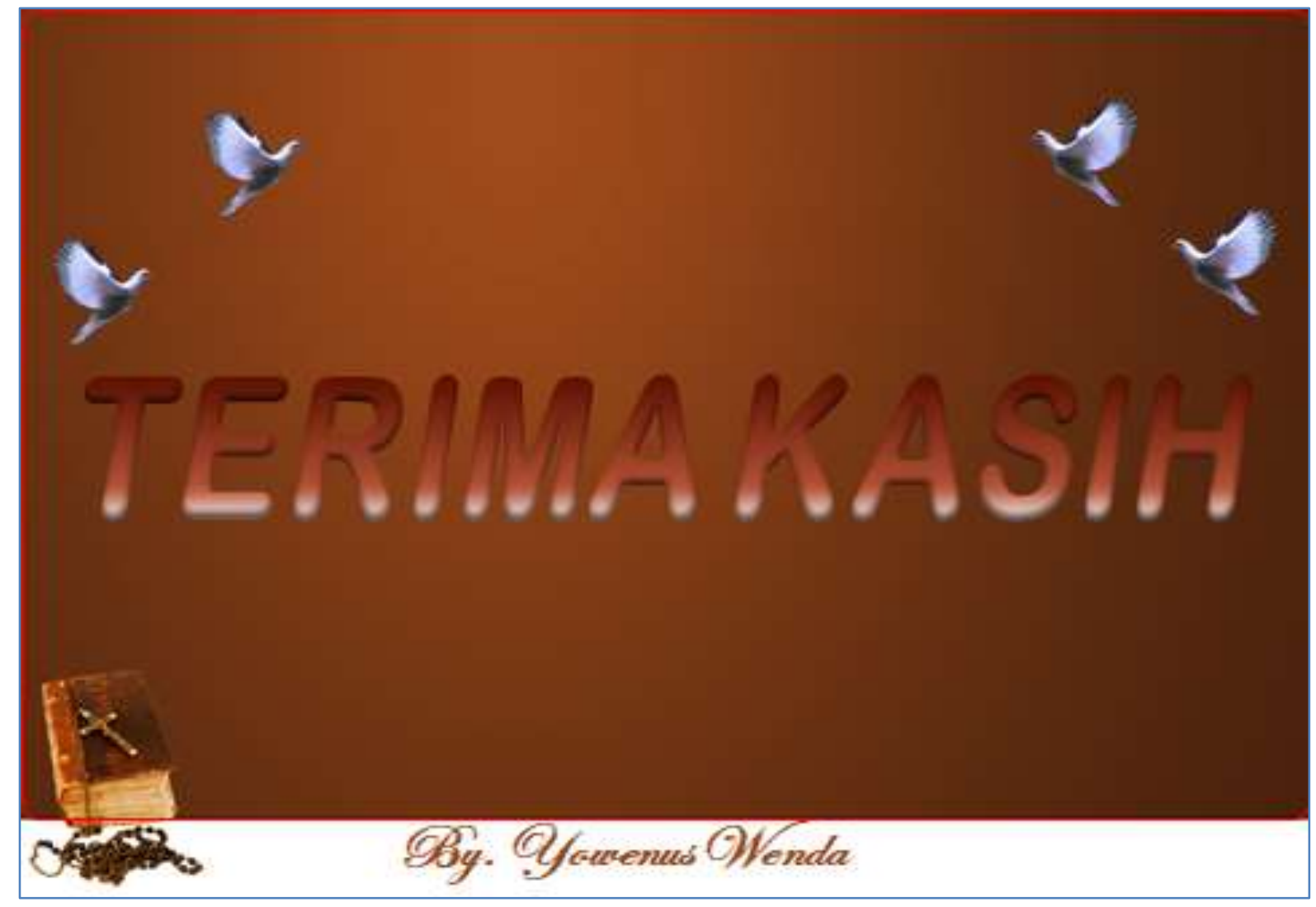

